\title{
Graduandos e suas crianças compartilhando os espaços da Universidade
}

\author{
Graduating and their children sharing the University premises \\ Alumnos de pre-grado y sus niños compartiendo los espacios de la \\ Universidad
}

\author{
Célia Regina da Silva Rocha \\ Regina Toni Loureiro de Freitas \\ Rita de Cássia Frenedozo \\ Simone Ferreira da Silva Domingues
}

Nas instituições que atuam diretamente com o Ensino Superior, estão matriculados cerca de seis milhões de alunos, dos quais aproximadamente $74 \%$ estudam em instituições privadas. De acordo com o Instituto Nacional de Estudos e Pesquisas Educacionais Anísio Teixeira [MEC/ INEP] (2009), órgão vinculado ao Ministério da Educação e do Desporto, dos alunos matriculados, $62,3 \%$ estão no período noturno e tentam conciliar situações referentes às realizações pessoal e profissional. Na Universidade privada, predominam jovens oriundos de famílias com rendas mensais mais baixas e escolaridade inferior (Augusto, 2005; Mutichelli, 1980; Pimenta, 2001). Nessas famílias, os jovens começam a trabalhar mais cedo para complementar a renda familiar, o que retarda sua formação acadêmica (Mendes, 1986; Pimenta, 2001). Muitos desses jovens já possuem filhos ou crianças sob sua responsabilidade e que fazem parte de sua rotina diária. Aos alunos nessas condições, que conciliam os estudos e suas crianças, sempre cabe a sensação de "estar em falta" com elas, mesmo que as responsabilidades sejam compartilhadas com as demais pessoas de seu convívio.

Outra questão presente na vida destes universitários refere-se ao orgulho de estarem matriculados em um curso universitário, uma vez que, em muitas famílias, estes jovens são os primeiros a frequentarem a Universidade, daí a importância em compartilhar esta conquista com os demais familiares (Augusto, 2005; Pimenta, 2001).

$\mathrm{Na}$ Universidade Cruzeiro do Sul, os alunos do curso de Psicologia manifestaram o desejo para as professoras de que seus filhos pudessem conhecer a instituição onde estudavam. A solicitação foi percebida como uma necessidade dos alunos de estreitar os laços e melhorar as relações entre eles e as crianças com quem mantinham relações de afetividade intensa, bem como de aproximar essas crianças do espaço universitário.

Compreendendo que o ambiente acadêmico provoca mudanças significativas no estudante, proporcionando o compartilhar de ideias e experiências (Schleich, Polydoro, \& Santos, 2006), as professoras desenvolveram um projeto que pudesse ir além de uma visita, mas que proporcionasse uma situação de interação e aprendizagem para os alunos.

O projeto foi desenvolvido com uma proposta que possibilitou a implantação do projeto "Dia da Criança", que, desde 2006, é realizado no mês de outubro e tornou-se uma atividade que faz parte do Projeto Político Pedagógico do curso de Psicologia da Universidade Cruzeiro do Sul (2008). Esta atividade foi iniciada no campus São Miguel e, a partir de 2008, foi estendida para os alunos de outro campus e de outros cursos.

No ano de 2006, para a atividade realizada no campus São Miguel, foram convidados 56 alunos, destes, compareceram 50 alunos e 68 crianças; em 2007, dos 71 alunos convidados, participaram 67 alunos e 101 crianças. Em 2008, convidamos 92 alunos do campus São Miguel, dos quais participaram 36 alunos e 42 crianças. No campus Anália Franco, foram convidados 77 alunos, dos quais compareceram 11 alunos e 30 crianças. No ano de 2009, dos 96 alunos convidados em São Miguel, compareceram 80 alunos e 76 crianças e, no campus Anália Franco, dos 92 alunos convidados, participaram 83 alunos e 73 crianças.

Os alunos participavam da atividade trazendo as "suas crianças" e/ou desenvolvendo atividades na condição de: 1) organizadores do evento, 2) monitores e recreadores (monitorando, criando elaborando e executando as ativida- 
des de recreação, jogos e brincadeiras), 3) auxiliares (auxiliando na organização, confeccionando cartazes, convites e adereços) ou 4) observadores (com ou sem crianças).

Divididas em pequenos grupos de faixa etária, as crianças foram encaminhadas para conhecer os espaços da Universidade: salas de aula, laboratórios, brinquedoteca e área de convivência. Após a visitação, foram levadas para um espaço onde puderam participar de jogos, brincadeiras e interagir com professores e alunos presentes.

Partindo de uma abordagem qualitativa, os professores puderam analisar os resultados do projeto. Uma das possibilidades foi que, durante as atividades, eles puderam se aproximar dos alunos e conhecer um pouco melhor a sua trajetória escolar. Constataram que alguns alunos ingressaram na Universidade no final da adolescência, saindo direto do Ensino Médio para o Superior e outros se afastaram da escola, retomando os estudos mais tarde, casados e com filhos, mais maduros e centrados em seus objetivos acadêmicos e profissionais. Tais resultados corroboram os de Mendes (1986) e os de Pimenta (2001). Além disso, verificaram que, ao trazer a "sua criança", os alunos demonstravam satisfação e orgulho ao apresentá-la às professoras e aos demais colegas.

A participação das crianças de 0 a 3 anos foi muito importante, pois, na brinquedoteca, elas puderam exercitar o ato de brincar, que é uma atividade envolvente, interessante e informativa, fazendo com que a criança aprenda consigo mesma, com os objetos e com as pessoas envolvidas na atividade lúdica (Macedo, Petty \& Passos, 2005). Quanto à interação das crianças e monitores, observou-se que elas, apesar da pouca idade, haviam atribuído sentido àquela experiência. A partir do conhecimento e visitação da instituição, as crianças de 4 a 12 anos relataram seu desejo de que, quando forem "grandes", estudar na Universidade. A partir da visita, as crianças manifestaram seu interesse pelas profissões, ao mesmo tempo em que desmistificaram as fantasias sobre o que é Universidade, passando a concebê-la como um espaço no qual elas também podem ser inseridas não somente quando se tornarem adultas, mas também enquanto crianças, pertencendo a este espaço de forma física e emocional.

Desta forma, a Universidade sai do plano da imaginação e passa a fazer parte do mundo real destas crianças, mundo do qual, dentro em breve, ela fará parte. Isso pôde ser observado no relato feito por uma aluna quando descreveu que a atividade despertou na "sua criança" o interesse em retornar à Universidade daqui a algum tempo na condição de aluno. No relato de outro aluno, ele afirma que o fato de participar da atividade com seus dois filhos favoreceu e estreitou os laços emocionais e familiares. Graduandos emocionalmente seguros tornam-se mais equilibrados e capazes de desenvolver suas potencialidades com competência (Pimenta, 2001).

A Universidade não pode desvincular a realidade educativa do componente humano, já que, ao se planificar o ensino, deve-se ter em conta a diversidade dos indivíduos, não apenas pelas características de personalidade, mas, principalmente, por suas distintas condições sociais (Augusto, 2005; Mutichelli, 1980; Pimenta, 2001; Urquijo, 2002). A atividade do "Dia das Crianças" considerou os interesses e necessidades dos alunos, buscando minimizar a sensação deles de estar "em falta"; além disso, favoreceu a confiança entre o aluno e a "sua criança", pois, ao sair de casa para ir à Universidade, a criança imediatamente identifica o local e se sente segura.

Neste sentido, partimos da premissa de que, no trabalho educativo cotidiano, não existe uma aprendizagem meramente cognitiva ou racional, pois os graduandos não deixam os aspectos afetivos do lado de fora da sala de aula no momento em que estão interagindo com os chamados objetos de conhecimento, ou não deixam latentes seus sentimentos - afetos e relações interpessoais - enquanto pensam; essa interação é constante e indissociável.

Concluímos que o projeto favoreceu a relação entre criança e alunos e possibilitou aos graduandos exercitarem suas competências e habilidades fundamentais para uma aprendizagem permanente (Stein, 1999), como também para sua futura atuação profissional (Santos, 2007). Nesse sentido, é de primordial importância relatar as atividades realizadas por graduandos para visibilidade positiva, ampliada e qualificada da Universidade perante a comunidade acadêmica, possibilitando, a partir dessa experiência, que outros projetos sejam desenvolvidos nessa direção para alcance da sociedade civil.

\section{Referências}

Augusto, M. H. O. (2005). Retomada de um legado intelectual: Marialice Foracchi e a Sociologia da juventude. Tempo Social, 17(1), 11-33.

Macedo, L., Petty, A. L. N, \& Passos, N. C. (2005). Os jogos e o lúdico na aprendizagem escolar. Porto Alegre: Artmed.

Mendes, A. (1986). O ensino superior noturno e a democratização do acesso à Universidade. Debates e Proposta INEP. Revista Brasileira de Estudos Pedagógicos, 67(157), 617-647.

Ministério da Educação e do Desporto. (2009). Censo da Educação Superior. Instituto Nacional de Estudos e Pesquisas Educacionais Anísio Teixeira. Brasília: MEC/INEP. Recuperado: 10 set. 2010. Disponível: http://www.inep.gov.br/download/superior/ censo/2004/resumo_tecnico_050105.pdf

Mucchielli, R. (1980). A formação de adultos. São Paulo: Martins Fontes.

Pimenta, M. M. (2001). Jovens em transição: um estudo sobre a transição para a vida adulta entre estudantes universitários em São Paulo. Dissertação de mestrado, Faculdade de Filosofia, Letras e Ciências Humanas da Universidade de São Paulo, São Paulo. 
Santos, M. S. (2007). Integração e diferença em encontros disciplinares. Revista Brasileira de Ciências Sociais, 22(65), 5160.

Stein, D. (2008). Situated learning in adult education. Recuperado: 05 de out 2010. Disponível: http://www.ericir.syr.edu?ERIC

Schleich, A. L. R., Polydoro, S. A. J., \& Santos, A. A. A. (2006). Escala de Satisfação com a experiência acadêmica de estudante do ensino superior. Aval. Psicol., 5(1), 11-20.
Universidade Cruzeiro do Sul. (2008). Projeto Político Pedagógico do Curso de Psicologia (Edição Revisada). São Paulo: Autor.

Urquijo, S. (2002). Auto-concepto y desempeno acadêmico en adolescentes. Relaciones con sexo, edad e instituición. PsicoUSF, 7(2), 211-218.

\section{Sobre as autoras:}

Célia Regina da Silva Rocha (célia.rocha@cruzeirodosul.edu.br, crsrocha@gmail.com)

Universidade Cruzeiro do Sul

Regina Toni Loureiro de Freitas (regina.freitas@cruzeirodosul.edu.br)

Universidade Cruzeiro do Sul

Rita de Cássia Frenedozo (rita.frenedozo@cruzeirodosul.edu.br)

Universidade Cruzeiro do Sul

Simone Ferreira da Silva Domingues (simone.domingues@cruzeirodosul.edu.br)

Universidade Cruzeiro do Sul

Endereço para correspondência:

Regina Toni Loureiro de Freitas

Universidade Cruzeiro do Sul.

Rua Dr. Usiel Cirillo, no. 225 - Vila Jacuí

São Paulo, SP,

CEP 08060-070 